\title{
PELVIC ORGAN PROLAPSE- A CONCERN
}

\author{
Bhakti Gurjar1, Kshama Kedar²
}

${ }_{1}^{1}$ Assistant Professor, Department of Obstetrics and Gynaecology, Indira Gandhi Government Medical College and Hospital, Nagpur. ${ }^{2}$ Associate Professor, Department of Obstetrics and Gynaecology, Indira Gandhi Government Medical College and Hospital, Nagpur.

\section{ABSTRACT}

\section{BACKGROUND}

Pelvic organ prolapse is a downward descent of pelvic organs and results in protrusion of the vagina and the uterus. It often provides additional symptoms to patient's life already complicated by menopause. There has been a considerable variation in presentation depending on numerous variables like age, ethnicity, education and symptoms.

Aim- Present study aims at studying various factors governing symptomatology and treatment choice of women in perimenopausal age group with uterovaginal prolapse in a central Indian population.

\section{MATERIALS AND METHODS}

This was a prospective study in which, all women attending Gynaecology Outpatient Department of Indira Gandhi Government Medical College, Nagpur presenting with pelvic organ prolapse over a period of 3 years from January 2013 to December 2015 were studied. They were studied for differences in sociodemographic factors, treatment choices and followed up for a period of 6 months after surgical/conservative treatment.

\section{RESULTS}

A total of 256 women were studied. According to our study, the risk of prolapse increased with age, increasing parity and increasing body mass index (BMI). Duration of symptoms ranged from 2 months to 15 years with $26.4 \%$ suffering for more than 5 years. Younger women were more likely to present earlier, opting more commonly for surgical treatment.

\section{CONCLUSION}

There is a need for increasing awareness as well as primary prevention regarding uterovaginal prolapse in general population and especially in perimenopausal age group. This can be instrumental in early access to health care system.

\section{KEYWORDS}

Pelvic Organ Prolapse (POP).

HOW TO CITE THIS ARTICLE: Gurjar B, Kedar K. Pelvic organ prolapse- A concern. J. Evolution Med. Dent. Sci. 2017;6(14):10801083, DOI: $10.14260 / \mathrm{Jemds} / 2017 / 234$

\section{BACKGROUND}

Pelvic organ prolapse (POP) is a downward descent of pelvic organs and results in protrusion of the vagina and the uterus. Because these displacements are each associated with defects in integrated connective tissue structures, they may each be considered as pelvic hernia. 316 million women worldwide as of 2010 ( $9.3 \%$ of all females) were affected by POP.

Women in developed countries who have access to modern health care can benefit from the advances that have been made in treating prolapse. If the problem is viewed from a worldwide perspective, the scope of suffering is much greater. In areas of high parity and little or no access to health care, countless women suffer from problems associated with pelvic organ prolapse with no real possibility of resolution.

Financial or Other, Competing Interest: None.

Submission 24-01-2017, Peer Review 05-02-2017,

Acceptance 07-02-2017, Published 15-02-2017.

Corresponding Author:

Dr. Bhakti Gurjar,

Assistant Professor,

Department of Obstetrics and Gynaecology,

Indira Gandhi Government Medical College

\& Hospital, Nagpur.

E-mail: drbhaktigurjar@ymail.com

DOI: $10.14260 /$ jemds $/ 2017 / 234$
A brief review of the history of treatment of prolapse is helpful in understanding modern treatments available and acceptable to the women. Because it was mentioned in the writings of Hippocrates and Galen, prolapse was clearly known to the ancients. Early treatments may seem quaint by today's standards. Fortunately, others have not survived. Vaginal packing, tampons, massages, and exercises were used with some success. Other women were suspended from their feet for a period of 24 hours to treat prolapse.

Rodericus A. Castro advised that prolapse should be attacked with a red hot iron as if to burn it, when fright would cause it to recede into the vagina. Various caustics were used, including silver nitrate, nitric acid, acid nitrate of mercury, hot metal, and sulfuric acid. ${ }^{1}$ Fortunately, we have come a long way into an era of more rational \& scientific treatment.

In $21^{\text {st }}$ century, in spite of having knowledge \& skill of a gamut of prolapse surgeries still in a developing country like India POP is even more of a concern as women are less likely to seek medical care or report late to a healthcare centre owing to lack of awareness, education and poverty. It adds symptoms to patient's life, which most of the times is, already complicated by menopause. Although mortality is negligible, but there is significant morbidity or deterioration of lifestyle. 


\section{Aims and Objectives}

Present study aims at studying various factors governing symptomatology and treatment choice of women with uterovaginal prolapse in a central Indian population.

\section{MATERIALS AND METHODS}

\section{Study Design}

Prospective observational study.

\section{Inclusion Criteria}

All women attending Gynaecology OPD of Indira Gandhi Government Medical College, Nagpur presenting with signs and symptoms of POP who consented to be a part of study were included. This is a teaching institute \& prime referral centre of central India for nearby states.

\section{Exclusion Criteria}

Women without any symptoms of POP and Women with symptoms of POP not consenting to be the part of study were excluded.

\section{Time Period}

3 years - Jan. 2013 to Dec. 2015.

\section{Methodology}

Initial evaluation included symptomatology and sociodemographic factors like age, parity, body mass index, sexual activity and menopausal status. Pre-existing morbidities like chronic cough and medical conditions governing treatment choice like diabetes, hypertension were noted. After a thorough history taking, women were physically examined and severity of the prolapse was graded as per POP-Q Classification. It was preferred over other methods of grading like Baden-Walker and Shaw's Classification as it is more defects specific \& no subjectivity. Presence or absence of Stress Urinary Incontinence (SUI) was also noted. Blood, urine and imaging investigations were performed as and when required.

All available treatment options as per age, parity and sexual activity of the patient were discussed. Surgical treatment choices included vaginal hysterectomy with or without anterior and/or posterior compartment defect repair as well as fertility and uterus sparing surgeries. Postoperative complications if any were noted. Women who were not willing for surgical treatment or were deemed unfit for a surgical intervention were given a choice of conservative or non-surgical approach. It included pelvic floor exercises (Kegel), Vaginal estradiol cream application and Pessary insertion. Final treatment choice of the patient was respected. Women who opted for Pessary insertion were taught about Pessary care and need for regular followup was impressed upon. All women were followed up for a period of 6 months after surgical/conservative treatment. Comparison of treatment choices between surgically treated and nonsurgically treated groups was done using Chi-square test.

\section{RESULTS}

The present study was conducted at a tertiary care centre catering to the health needs of a major female population of central India, with an average of 50 to 60 women attending the Gynaecology Outpatient Department daily. Over a period of 3 years from January 2013 to December 2015, a total of
256 women reported to OPD with history and examination findings consistent with Pelvic Organ Prolapse.

Table 1 shows Age and parity wise distribution of study population. Although majority of women belonged to the age group of 40-49 years, most of the women who underwent conservative management belonged to a higher age group. Most of the women had given birth to 2 or 3 children, out of which very few i.e. 21 women $(8.2 \%)$ had a history of previous caesarean section/sections. This finding reinforces the theory that vaginal delivery contributes to pelvic floor damage, proposed as a causative factor for Prolapse.

\begin{tabular}{|c|c|c|c|c|c|}
\hline $\begin{array}{c}\text { Age } \\
\text { Group in } \\
\text { Years }\end{array}$ & $\begin{array}{c}\text { Surgically } \\
\text { Treated }\end{array}$ & $\begin{array}{c}\text { Conser- } \\
\text { vatively } \\
\text { Treated }\end{array}$ & Total & Parity & $\begin{array}{c}\text { Number } \\
\text { of } \\
\text { Women }\end{array}$ \\
\hline $20-29$ & 2 & 0 & 2 & Nullipara & 2 \\
\hline $30-39$ & 28 & 0 & 28 & Para 1 & 39 \\
\hline $40-49$ & 75 & 7 & 82 & Para 2 & 58 \\
\hline $50-59$ & 37 & 28 & 65 & Para 3 & 73 \\
\hline $60-69$ & 39 & 22 & 61 & Para 4 & 48 \\
\hline $70-79$ & 1 & 17 & 18 & Para 5 & 24 \\
\hline Total & $\mathbf{1 8 2}$ & $\mathbf{7 4}$ & $\mathbf{2 5 6}$ & $\begin{array}{c}\text { Para 6 } \\
\text { and above }\end{array}$ & $\mathbf{1 2}$ \\
\hline \multicolumn{6}{|c|}{ Table 1. Age and Parity Wise Distribution of Women } \\
\hline
\end{tabular}

Table 2- It was also found that most women presenting with POP were having a higher BMI. Majority women i.e. 109 had a BMI falling in Overweight category while 46 women were actually obese. Exact mechanism for this predisposition largely remains unknown.

\begin{tabular}{|c|c|}
\hline BMI & Number of Women \\
\hline$<18.5$ & 45 \\
\hline $18.5-24.9$ & 56 \\
\hline $25-29.9$ & $\mathbf{1 0 9}$ \\
\hline$>30$ & 46 \\
\hline \multicolumn{2}{|c|}{ Table 2. Relationship with BMI } \\
\hline
\end{tabular}

Table 3 shows that a majority of women of the study group presented after 3 to 4 years of suffering. Duration of symptoms ranged from 2 months to 15 years with $26.4 \%$ suffering for more than 5 years. This finding underlines the social impact of this condition. Furthermore, late presentation represents not only the social taboo associated with the condition, but also indicates a lack of awareness, secondary position of a female in the family and possibly nonavailability of primary health care. Something coming out per vaginum was the commonest chief complaint; however, other symptoms like Urinary frequency, Dysuria, Pelvic Pain, Constipation and SUI were also not uncommon.

\begin{tabular}{|c|c|c|c|c|c|c|}
\hline $\begin{array}{c}\text { Symptoms } \\
\text { Duration } \\
\text { in Yrs. }\end{array}$ & $\begin{array}{c}\text { Something } \\
\text { Coming } \\
\text { out PV }\end{array}$ & $\begin{array}{c}\text { Urinary } \\
\text { Complaints }\end{array}$ & $\begin{array}{c}\text { Pelvic } \\
\text { Pain }\end{array}$ & $\begin{array}{c}\text { Constipa- } \\
\text { tion }\end{array}$ & SUI & Total \\
\hline$<1$ & 0 & 0 & 5 & 7 & 0 & 12 \\
\hline $1-2$ & 8 & 8 & 6 & 10 & 4 & 36 \\
\hline $2-3$ & 3 & 0 & 9 & 8 & 8 & 28 \\
\hline $3-4$ & 40 & 9 & 8 & 5 & 2 & 64 \\
\hline $4-5$ & 31 & 7 & 8 & 2 & 0 & 48 \\
\hline$>5$ & 64 & 4 & 0 & 0 & 0 & 68 \\
\hline Total & $\mathbf{1 4 6}$ & $\mathbf{2 8}$ & $\mathbf{3 6}$ & $\mathbf{3 2}$ & $\mathbf{1 4}$ & $\mathbf{2 5 6}$ \\
\hline
\end{tabular}

Table 3. Duration of Symptoms and Presenting Symptoms 
Out of a total 256 women, 182 women opted for surgical management while 74 women opted for non-surgical management. Each group was further subdivided into premenopausal and post-menopausal subgroups.

Table 4 shows distribution of women in the surgically treated group. It is evident from the table that majority of women in premenopausal group had lesser degrees of prolapse when compared with the postmenopausal group. Vaginal hysterectomy with or without anterior and/or posterior compartment repair was the most commonly performed surgery. One of the women had a huge cervical fibroid as a cause of prolapse and it was treated by hysterectomy. 8 younger women opted for conservative surgeries like Fothergill Procedure (4.3\%) and Abdominal sling surgery in 9 women (4.9\%). Only 5 of the women who had demonstrable SUI opted for surgical correction, which was done by Trans-Obturator Tape Repair. Rest of the women with SUI opted for medical management which was given in consultation with Urologist. Transvaginal mesh was not used in any of the Vaginal Hysterectomy owing to concerns about its safety. Two women who presented with vault prolapse following Vaginal Hysterectomy underwent Abdominal sacropexy.

\begin{tabular}{|c|c|c|c|c|c|}
\hline POP-Q & Stage & Stage & Stage & Stage & Total \\
Menopause & $\mathbf{1}$ & $\mathbf{2}$ & $\mathbf{3}$ & $\mathbf{4}$ & \\
\hline Pre-menopausal & 1 & 71 & 31 & 2 & 105 \\
\hline Post-menopausal & 8 & 21 & 44 & 4 & 77 \\
\hline Total & $\mathbf{9}$ & $\mathbf{9 2}$ & $\mathbf{7 5}$ & $\mathbf{6}$ & $\mathbf{1 8 2}$ \\
\hline Table 4. Distribution of Women in Surgically Treated \\
Group \\
\hline
\end{tabular}

A comparison was done between surgically treated and non-surgically (conservatively) treated group using Chisquare test. It showed that women in the premenopausal age group opted more commonly for surgical treatment when compared to post-menopausal group and this difference was statistically significant with a p value of $<0.05$ (Table 5).

\begin{tabular}{|c|c|c|c|}
\hline Age & $\begin{array}{c}\text { Non-surgical } \\
\text { Treatment }\end{array}$ & \begin{tabular}{|c|} 
Surgical \\
Treatment \\
\end{tabular} & $\begin{array}{l}P \text { value } \\
<005\end{array}$ \\
\hline \begin{tabular}{|l|} 
Pre-menopausal \\
\end{tabular} & 7 & 105 & $\begin{array}{l}<0.05 \\
(\text { Sionificont) }\end{array}$ \\
\hline Post-menopausal & 67 & 77 & \\
\hline
\end{tabular}

\section{DISCUSSION}

Pelvic Organ Prolapse is a significant public health problem in developing world, with literature being limited. Symptoms of prolapse definitely deteriorate the quality of life of women (Shrestha B). ${ }^{2}$ Few studies are available focussing on the

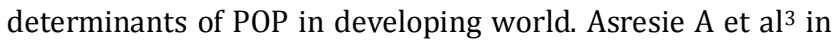
their unmatched controlled study found that age more than 40 years was independent risk factor for POP. This was consistent with our finding that most of our women belonged to the age group of 40 years and above. Kinman CL et al ${ }^{4}$ studied the relationship between age and pelvic organ prolapse bother in women with POP stage 2 and more. They concluded that women in $6^{\text {th }}$ and $7^{\text {th }}$ decade of life experienced higher level of bother from POP than older or younger women with the same stage of prolapse.
Most of the women had given birth to 3 or more children as per our study. Islam RL et $\mathrm{al}^{5}$ in their study on Bangladeshi women found that having 3 or more children was positively linked with having at least one symptom of pelvic floor disorder, which was consistent with our study. Very few i.e. 21 of our women $(8.2 \%)$ had a history of previous caesarean section/sections. Other studies Akter F, 6 Zeleke BM7 showed similar results. Howard D et al 8 in their study focussed on vaginal birth as a primary risk factor for the development of pelvic floor disorders and have also suggested steps to prevent or minimise the development of pelvic floor problems like moderating forceps use and utilising risk assessment tools to offer caesarean delivery to those at greatest risk. Hallock $\mathrm{JL}^{9}$ study has concentrated on role of childbirth in development of single or multiple coexisting pelvic floor disorders.

We found that most women presenting with POP were having a higher Body Mass index. Ghandour L et $\mathrm{al}^{10}$ in their study also found that a BMI of $>25 \mathrm{Kg} / \mathrm{m}^{2}$ was an independent risk factor for the presence of Pelvic Floor Disorder symptoms. Elbiss HM,11 de Sam Lazaro S,12 Chen $Y,{ }^{13}$ Shimonov $\mathrm{M}^{14}$ have also found a correlation between POP and BMI.

Mazloomdoost D et al ${ }^{15}$ tried to understand the barriers to seeking care for POP and sought to assess attitude, knowledge and practice patterns of primary care providers of POP. They found that although primary care providers within a large healthcare system were familiar, more with urinary incontinence than POP, nearly one fifth were unaware of where to refer the patient. Their findings partly explain late reporting of women to tertiary care hospitals as seen in Table 3.

74 of our women opted for non-surgical treatments, pelvic floor exercises being one of them. Hagen et al ${ }^{16}$ have also found usefulness of pelvic floor training for secondary prevention of pelvic organ prolapse in their multicentre randomised controlled trial. Non-surgical interventions may provide an opportunity to address the significant burden of POP especially in underdeveloped areas as per Fitchett JR ${ }^{17}$ study. However, finding the efficacy of this treatment method was beyond the purview of our study.

Majority of our women underwent hysterectomy with pelvic floor repair. Surgical advances in pelvic floor repair in last two decades along with increased anaesthesia safety have probably led to increase in the number of prolapse surgeries.

The first vaginal hysterectomy for prolapse was performed by Samuel Choppin of New Orleans in 1861. In 1990s, pelvic anatomist John O. L. DeLancey of Michigan published a biomechanical analysis of normal vaginal anatomy. Understanding about pelvic floor defects and pelvic floor reconstructive surgeries have greatly evolved since then.

Use of Transvaginal mesh was steadily increasing till around 2008, after which its use declined owing to concerns about mesh complications. U.S. Food and Drug Administration warned in July 2011 that the use of a transvaginal mesh in treating vaginal prolapses is associated with side effects including pain, infection, and organ perforation. According to the FDA, serious complications are "not rare." We did not use transvaginal mesh in any of our women. 
Most of the women (67) who underwent conservative management belonged to a higher age group (postmenopausal), while 105 of the younger (premenopausal) women opted more commonly for surgical intervention in our study. Our finding was consistent with Sullivan SA ${ }^{18}$ et al who studied a retrospective cohort study over 1 year with an aim of determining patient desire for either surgical or conservative treatment, as well as the actual treatment chosen and received after the first visit and 1 year later. To obtain predictors of choice, baseline demographic characteristics were obtained by them. They found that women who desired surgery were more likely to be younger, sexually active, have more advanced prolapse and have more bothersome symptoms. They concluded that younger women are more likely to either opt for surgery initially or change their treatment plan from conservative to surgical.

\section{CONCLUSION}

A total of 256 women were studied. According to our study, the risk of prolapse increased with age, increasing parity and increasing body mass index. Duration of symptoms ranged from 2 months to 15 years with $26.4 \%$ suffering for more than 5 years. Younger women were more likely to present earlier, opted more commonly for surgical treatment.

However, our study was limited by a small sample size. We conclude that there is a need of increasing awareness in women of all age groups, especially perimenopausal age groups about seeking medical care and treatment options for the management of Pelvic Organ Prolapse.

\section{REFERENCES}

[1] John RA, Howard JW. Textbook of Te Linde's operative gynecology. 10 $10^{\text {th }}$ edn. Section VII-surgery for corrections of defects in pelvic support and pelvic fistulas, Chapter-36A - Pelvic organ prolapse: basic principles 2015.

[2] Shrestha B, Onta S, Choulagai B, et al. Uterine prolapse and its impact on quality of life in the JhaukhelDuwakot health demographic surveillance site, Bhaktapur, Nepal. Glob Health Action 2015;8:28771.

[3] Asresie A, Admassu E, Setegn T. Determinants of pelvic organ prolapse among gynecologic patients in Bahir Dar, North West Ethiopia: a case-control study. Int J Womens Health 2016;8:713-9.

[4] Kinman CL, Lemieux CA, Agrawal A, et al. The relationship between age and pelvic organ prolapse bother. Int Urogynecol J 2016.

[5] Islam RM, Bell RJ, Billah B, et al. The prevalence of symptomatic pelvic floor disorders in women in Bangladesh. Climacteric 2016;19(6):558-64.
[6] Akter F, Gartoulla P, Oldroyd J, et al. Prevalence of, and risk factors for, symptomatic pelvic organ prolapse in rural Bangladesh: a cross-sectional survey study. Int Urogynecol J 2016;27(11):1753-9.

[7] Zeleke BM, Bell RJ, Billah B, et al. Symptomatic pelvic floor disorders in community-dwelling older Australian women. Maturitas 2016;85:34-41.

[8] Howard D, Makhlouf M. Can pelvic floor dysfunction after vaginal birth be prevented? Int Urogynecol J 2016;27(12):1811-5.

[9] Hallock JL, Handa VL. The epidemiology of pelvic floor disorders and childbirth: an update. Obstet Gynecol Clin North Am 2016;43(1):1-13.

[10] Ghandour L, Minassian V, Al-Badr A, et al. Prevalence and degree of bother of pelvic floor disorder symptoms among women from primary care and specialty clinics in Lebanon: an exploratory study. Int Urogynecol J 2017;28(1):105-18.

[11] Elbiss HM, Osman N, Hammad FT. Prevalence, risk factors and severity of symptoms of pelvic organ prolapse among Emirati women. BMC Urol 2015;15:66.

[12] De Lazaro SS, Nardos R, Caughey AB. Obesity and pelvic floor dysfunction: battling the bulge. Obstet Gynecol Surv 2016;71(2):114-25.

[13] Chen Y, Johnson B, Li F, et al. The effect of body mass index on pelvic floor support 1 year postpartum. Reprod Sci 2016;23(2):234-8.

[14] Shimonov M, Groutz A, Schachter P, et al. Is bariatric surgery the answer to urinary incontinence in obese women? Neurourol Urodyn 2015;36(1):184-7.

[15] Mazloomdoost D, Westermann LB, Crisp CC, et al. Primary care providers attitudes, knowledge, and practice patterns regarding pelvic floor disorders. Int Urogynecol J 2016.

[16] Hagen S, Glazener C, McClurg D, et al. Pelvic floor muscle training for secondary prevention of pelvic organ prolapse (PREVPROL): a multicentre randomised controlled trial. Lancet 2017;389(10067):393402.

[17] Fitchett JR, Bhatta S, Sherpa TY, et al. Non-surgical interventions for pelvic organ prolapse in rural Nepal: a prospective monitoring and evaluation study. JRSM Open 2015;6(12):2054270415608117.

[18] Sullivan SA, Davidson ER, Bretschneider CE, et al. Patient characteristics associated with treatment choice for pelvic organ prolapse and urinary incontinence. Int Urogynecol J 2016;27(5):811-6. 